\title{
Editoriali/ Editorials
}

\section{Attitudes to psychosis: health professionals}

\author{
MAXINE X. PATEL
}

\section{INTRODUCTION}

Attitudes held by health professionals, especially those working in mental health, can profoundly influence the well-being of patients with psychosis. Thus, both health care provision and health outcomes are compromised, with resultant inequality. These attitudes are shaped by and vary according to prevailing cultural norms, in society at large, in health service organisations and within professional peer groups. Attitude studies focus on a variety of aspects including diagnosis and the choice of treatment options. Surveys and case vignette studies have been conducted on health professional groups, either individually or by comparing groups. Surveys have been used to assess attitudes but these are prone to a social desirability bias in that participants tend to answer in accordance with social norms rather than stating real attitudes. The use of case vignettes attempts to overcome this although, importantly, actual behaviour is not always concordant with stated attitudes, be they real or otherwise (Gray, 2002). This editorial highlights the key issues from the research field on attitudes held by psychiatrists, other mental health professionals, general health profes-

Address for correspondence: Dr. M.X. Patel. Division of Psychological Medicine. PO Box 68. Institute of Psychiatry \& GKT School of Medicine. De Crespigny Park, London SE5 8AF (United Kingdom).

Fax: +44-(0)20-7848.0572

E-mail: m.patel@iop.kcl.ac.uk

Declaration of Interest: Dr. Patel is currently funded by a special training fellowship (Health Services Research) from the Medical Research Council. She has previously worked on two clinical drug trials for Janssen-Cilag and has received consultation fees from the pharmaceutical industry. sionals and students. Attitudinal differences etween professional groups are considered. The impact of attitudes, particularly in terms of stigmatisation, is outlined together with possible methods for changing adverse attitudes.

\section{PSYCHIATRISTS}

\section{Diagnosis and aetiology}

Standardised diagnostic criteria encourage psychiatrists to practice in a uniform manner but use of these criteria has not overcome varying attitudes of psychiatrists as to when and where the diagnosis of a psychotic disorder should be used. According to a UK case vignette study, sociodemographic factors may outweigh clinical characteristics when formulating a diagnosis, as white patients were more likely than African-Caribbeans to be diagnosed with schizophrenia (Lewis et al., 1990). Indeed, the use of diagnostic labels is subject to debate and is also seen to be potentially stigmatising (Cape et al., 1994; Allison-Bolger, 1999).

Even where a diagnosis of a psychotic disorder is reached, the psychiatrist's attitudes towards this diagnosis can prevent him or her from sharing it with the patient and carers. In Japan, only $7 \%$ of psychiatrists reported that they always inform their patients of a diagnosis of schizophrenia (Ono et al., 1999). This could be interpreted as the psychiatrist reinforcing the acceptability of the associated stigma rather than attempting to challenge it.

Variation in attitudes regarding aetiological factors also exists. Whilst there is a general consensus amongst psychiatrists about the value of biological factors, older and more experienced UK psychiatrists also emphasised the importance of psychological factors, unlike their younger colleagues (Cape et al., 1994; Gallagher et al., 1987). 


\section{Treatment options}

Adverse attitudes held by psychiatrists can totally undermine the effectiveness of therapeutic interventions. Undoubtedly, there is damaging impact from the belief held by $91 \%$ of psychiatric trainees surveyed in USA, that people with schizophrenia are not able to develop a therapeutic alliance (Packer et al., 1994). Even where standard protocols are available, such as legal criteria for compulsory admission, their application is not necessarily standardised as the relative weight given to different factors in the decision-making process can vary greatly. As such, case vignette studies on compulsory admission have revealed differing weights given to perceived dangerousness, current mental state, illness duration and illness severity (Andrews et al., 1986; Dazzan \& Bhugra, 2000, Dazzan et al., 2001).

For therapeutic interventions, psychiatrists generally agree with one another that pharmacotherapy in conjunction with supportive or family / social intervention psychotherapy is appropriate (Andrews et al., 1986). However, a reluctance to treat patients with chronic mental illness is also evident and a sense of paternalism has been detected where psychiatrists generally did not consider 'patient preference' as an indication for antipsychotic depot use (Lambert et al., 2003). Wide variation in attitudes regarding depot antipsychotics are one cause of greatly differing prescribing practices for these drugs, with unfavourable depot attitudes further being associated with incomplete knowledge about depots (Walburn et al., 2001; Patel et al., 2003a; Patel \& David, in press). Attitudes regarding typical versus atypical antipsychotics also vary amongst psychiatrists. In particular, younger and less experienced psychiatrists were more likely than their older colleagues, to switch a patient from a typical to an atypical antipsychotic, based on an underlying assumption that typical antipsychotics are bound to cause side effects while atypicals virtually never do (Patel $e t$ al., 2003b).

\section{OTHER MENTAL HEALTH PROFESSIONALS}

\section{Community care}

Mental health professionals do not perceive patients with chronic mental illness as a preferred group to treat and therefore may try to avoid contact by referring elsewhere. This is possibly because most feel that little personal satisfaction can be gained and that there is not much hope for a satisfactory outcome (Mirabi et al. 1985). However, feelings of hopefulness in staff for their patients with schizophrenia can be reinforced by: clinical experience of working with clients who have been successful, working together with hopeful colleagues and guarding against the influence of colleagues without hope (Landeen et al., 1996).

Interestingly, the feeling of enhanced professional autonomy probably accounted for the finding that Canadian community-based mental health professionals were more likely than hospital-based professionals to feel that they made a positive difference to the lives of people with schizophrenia (Woodside et al., 1994). Similarly, different methods for community care may impact on professionals' attitudes (Murray \& Steffen, 1999).

\section{Clinical psychologists and psychoanalysts}

Few psychologists work with clients with psychosis, possibly due to the perception that they are less attractive to work with than others suffering from neurotic disorders who are often treated successfully. However, $91 \%$ of clinical psychologists (UK/ Eire) disagreed with the statement "schizophrenia is too severe a condition for psychologists to work with" (Gallagher et al., 1991). It is therefore unclear as to why few provide psychological input for this group. Where training for psychological management of psychotic symptoms has taken place (nurses and psychologists), significant increases in expectations of work satisfaction and in perceived empathy for the experiences of hallucinations and delusions have been reported (McLeod et al., 2002).

Similarly, involvement of psychoanalysts is somewhat rare. Lucas (2003) postulated that psychoanalysis was the only framework that offered clients a way to help them make sense of their experiences and therefore urged psychoanalysts to revitalise an analytic approach to schizophrenia. Michels (2003) counter-argued that psychoanalysis may provide merely one of the many possible frameworks for understanding psychotic experiences and how patients cope with them and secondly, that the contribution of psychoanalysis may be in supporting and reassuring staff and carers rather than directly influencing patients.

\section{Inter-profession group comparison studies}

There are attitudinal differences between health care professionals and the public as well as between the various groups of health professionals. These could result in conflicting messages for patients and thereby undermine the treatment process. Multidisciplinary cohesive team- 
work is therefore critical, with due attention paid to differences in opinion, together with patient involvement in the decision-making process.

In an Australian series of case vignette studies, all health professional groups were more likely than the public to believe that a person with schizophrenia would be discriminated against. They were also more pessimistic than the public about long-term prognosis, although psychiatric nurses were significantly less so than the other professional groups. Psychiatrists were less likely than general practitioners (GPs), psychologists and psychiatric nurses to endorse psychosocial and lifestyle interventions, although there was a general consensus amongst professional groups concerning the helpfulness of antipsychotics. Psychiatric nurses were also more likely than psychiatrists to believe that certain non-standard interventions (e.g. vitamins, minerals) would be helpful and that hospital admission would not be helpful (Jorm et al., 1997; 1999; Caldwell \& Jorm, 2000; 2001).

For staff working in one psychiatric hospital in Israel, cultural and educational factors appeared to shape their attitudes as patient rejection scores were higher among those born in USA (versus Europe/Israel) and among psychologists and social workers (versus other mental health professionals). Higher rejection scores were assigned to patients judged to be more irritable, manifestly psychotic and had impaired cognition (Heresco-Levy et al., 1999). In Italy, nursing staff were more pessimistic than other staff members about the psychosocial consequences of schizophrenia (Magliano et al.. 2002). Similarly, in China, psychiatric nurses were less liberal and had more negative attitudes toward the mentally ill than psychiatrists; especially regarding community rehabilitation. For example, nurses were significantly more likely than psychiatrists to disagree with the statement "Most women who were once patients in a mental hospital can be trusted to take care of babies" (Sevigny et al., 1999).

In essence, inter-professional group differences in attitudes abound. In particular, differences are found in attitudes regarding therapeutic and lifestyle interventions. prognosis and functional ability. Such differences could easily undermine the treatment process.

\section{GENERAL HEALTH PROFESSIONALS}

\section{Hospital Care}

Concerns about dangerousness and unpredictable behaviour of people with psychosis are very evident for general health professionals. In a combined survey of general doctors and medical students at one London teaching hospital, $54 \%$ felt that patients with schizophrenia posed a danger to others and $85 \%$ felt that these patients were unpredictable (Mukherjee et al., 2002). In Croatia, $37 \%$ of general hospital employees were afraid of patients with schizophrenia and $21 \%$ believed this group of patients to be mostly violent and dangerous (Filipcic et al. 2003). General hospital nurses in Turkey had more negative attitudes than physicians although no difference was apparent between the groups regarding the likely prognosis for schizophrenia (Aydin et al., 2003).

\section{Primary care}

In Scotland, GPs were less happy to have a patient with schizophrenia on their practice list and were more concerned about the risk of violence than for patients with depression or diabetes. Whilst these concerns may be based in reality, the resultant possible discrimination may cause such patients to have difficulty in registering with a GP and receiving integrated community-based health care (Lawrie et al., 1996; 1998). Worse still, UK primary-care practice nurses may avoid asking questions of patients with schizophrenia, during routine depot antipsychotic administration, for fear of "opening a can of worms" (Kendrick et al., 1998).

\section{STUDENTS}

Preclinical medical students have attitudes to mental illnesses similar to that of the public, whilst clinical medical students have similar attitudes to junior doctors, thus suggesting an attitudinal shift as medical education progress (Mukherjee et al., 2002; Thompson et al., 2002). During undergraduate psychiatric training in particular, general attitudes to psychiatry are said to become more favourable (Coodin \& Chisholm, 2001). However, in Australia, students also became more medically and 'authoritarian' oriented and less psychosocial and 'libertarian' oriented (Augustinos et al., 1985). Students have also highlighted staff's negative attitudes towards patients as being one of the least attractive aspects of their psychiatric training. Furthermore, there is conflicting evidence about these positive attitudinal changes being maintained at follow-up (Creed \& Goldberg, 1987; Baxter et al., 2001). In a comparison of Spanish medical and nursing students, no differences in knowledge about schizophrenia were noted although, as a combined group, $78 \%$ considered that people with schizophrenia were or could be dangerous or violent (Llerena et al., 2002). 


\section{IMPACT \& STIGMA}

Psychiatric patients are regarded by health professionals as "not easy to like" and "unsatisfying to treat" (Buchanan \& Bhugra, 1992). Such negative attitudes are stigmatising and discriminatory. From the patient's perspective, this can adversely impact on otherwise appropriate help-seeking behaviour. Indeed, services that are perceived as less stigmatising have lower drop-out rates (Gray, 2002). Similarly. health care provision and health outcomes for this group can be compromised as these attitudes influence the ability of doctors to identify, treat and refer patients with mental disorders (Buchanan \& Bhugra, 1992; Aydin et al., 2003). Furthermore, insufficient attention is paid to a patient's physical health needs due to the stigma or fear of the potential threat posed by these patients (Filipcic et al., 2003). Consequently, lack of adequate healthcare undoubtedly contributes to the unacceptably high mortality in schizophrenia in the UK (Gray, 2002). Unfortunately, the actual impact of staff attitudes on patient outcomes has not been adequately demonstrated, although Watson et al. (1980) found that health outcomes for patients with schizophrenia were adversely affected by 'authoritarian' attitudes (patient held accountable for own behaviour) whereas high 'protective benevolence' (friendly non-punitive, laissez-faire approach) was associated with improvement.

\section{CHANGING ADVERSE ATTITUDES}

Health professional attitudes to people with psychosis are shaped by and vary according to prevailing cultural norms, in society at large from early childhood onwards, in health service organisations and within professional peer groups from undergraduate training onwards. Further attitudinal changes may result from ongoing clinical experience although the changing societal values may also play a role (Buchanan \& Bhugra, 1992; Schulze \& Angermeyer, 2003). Evidently, health professionals have a responsibility to tackle their adverse attitudes, with resultant 'iatrogenic stigmatisation', as highlighted by Sartorius (2002) who asked:

How should we convince others that most people with mental illness retain many of their capacities and that their rights are often not respected if we do not show the way by our own behaviour?

The responsibility to enhance equity in healthcare for patients with mental illness lies with all health professionals (Hocking, 2003). Approaches at several levels, in several different ways and occurring concurrently are required, or such attempts will be undermined by causes of stigmatisation left unchallenged (Link, 2001). Resource allocation for mental health services and legal aspects regarding compulsory admission should be addressed at national and regional levels. At the systems level, programmes need to be instigated to identify and address such attitudes by implementation of new policies. Walter (1998) suggested three methods to improve attitudes, namely: (i) effective managerial intervention to improve work satisfaction and thereby service provision; (ii) social action interventions assisting patients to obtain better service and attitudes from providers; (iii) cognitive approaches combining direct teaching of material challenging prejudice, monitoring and changing pessimistic thinking regarding patient prognosis. Additionally, awareness of positive and successful people with psychotic illnesses might help to break the "them and us" mentality held by numerous health professionals (see "Open the Doors" anti-stigma campaign, www.openthedoors.com, 2004). Lastly, health professionals can also take both collective and individual action to challenge the stigma of mental illness, not least of all by addressing their own adverse attitudes. As such, they should never tolerate stigmatising language used in reference to those with mental illness, whatever the social situation (Summerfield, 2001; Gray, 2002).

\section{CONCLUSIONS}

Health professionals' attitudes to psychotic illnesses are a product of the social and cultural environment from early childhood, through clinical training and accumulative clinical experience. Inter-profession variation in attitudes should be considered within everyday clinical practice. Negative attitudes should never be considered acceptable, wherever and whenever encountered. Personal attitudes should be evaluated for the stigmatising and discriminatory value that they may possess. Further challenges to such attitudes should be made, as well as to the factors that reinforce them. Whilst some may argue that there is little point in further investigating adverse attitudes, as we are already aware that they exist, others would rightly agree that appropriate research tools need to be developed to identify and monitor attitudes and their actual impact on clinical practice behaviours. In this way, any intervention to address adverse attitudes can then be appropriately evaluated for its enduring effectiveness. Of course, all of this should occur in close consultation with those whom it most affects. Only then will health professionals be seen not to add to the burden faced by people with psychosis. 


\section{REFERENCES}

Allison-Bolger V.Y. (1999). IV: the original sin of madness - or how psychiatrists can stigmatise their patients. Intemational Journal of Clinical Practice 53. 627-630.

Andrews S.. Vaughan K.. Harvey R. \& Andrews G. (1986). A survey of practising psychiatrists" views on the treatment of schizophrenia. British Journal of Psychiatry 149. 357-364.

Augustinos M.. Schrader G.. Chynowerth R. \& Reid M. (1985). Medical students' attitudes towards psychiatry: a conceptual shift. Psychological Medicine 15.671-678.

Aydin N.. Yigit A.. Inandi T \& Kirpinar I. (2003). Attitudes of hospital staff toward mentally ill patients in a teaching hospital. Turkey. Intemational Joumal of Social Psychiatry 49, 17-26.

Baxter H., Singh S.P., Stander P. \& Duggan C. (2001). The attitudes of 'tomorrow's doctors' towards mental illness and psychiatry: changes during the final undergraduate year. Medical Education 35 , 381-383.

Buchanan A. \& Bhugra D. (1992). Attitude of the medical profession to psychiatry. Acta Psichiatrica Scandinarica 85, 1-5.

Caldwell T.M. \& Jorm A.F. (2000). Mental health nurses' beliefs about interventions for schizophrenia and depression: a comparison with psychiatrists and the public. Australian and New Zealand Joumal of Psychiatry 34, 602-611.

Caldwell T.M. \& A.F. Jorm (200I). Mental health nurses' beliefs about likely outcomes for people with schizophrenia or depression: A comparison with the public and other healthcare professionals. Australian and New Zealand Journal of Mental Health Nursing 10, $42-54$.

Cape G., Antebi D., Standen P. \& Glazebrook C. (1994). Schizophrenia: the views of a sample of psychiatrists. Journal of Mental Health 3, 105-113.

Coodin S. \& Chisholm F. (2001). Teaching in a new key: Effects of a Co-taught seminar on medical students' attitudes toward schizophrenia. Psychiatric Rehabilitation Journal 24, 299-302.

Creed F. \& Goldberg D. (1987). Student's attitude to psychiatry. Medical Education 21, 227-234.

Dazzan P. \& Bhugra D. (2000). Use of the Mental Health Act criteria in the decision-making process for compulsory admissions: a study of psychiatrists in South London. Medicine, Science and the Law 40, 336-344.

Dazzan P.. Bhugra D. Carta M.G. \& Carpiniello B. (2001). Decision making process for compulsory admission: study of a group of psychiatrists of Sardinia. Italy. Epidemiologia e Psichiatria Sociale 10 , 37-45.

Filipcic I., Pavicic D.. Filipcic A.. Hotujac L., Begic D., Grubsin J. \& Dordevic V. (2003). Attitudes of medical staff towards the psychiatric label "schizophrenic patient" tested by an anti-stigma questionnaire. Collegium Antropologicum 27. 301-307.

Gallagher A.G., Gernex T. \& Baker L.J.V. (1991). Beliefs of psychologists about schizophrenia and their role in its treatment. Irish Journal of Psychology 12, 393-405.

Gallagher B.J.. Jones B.J. \& Barakat L.P. (1987). The attitudes of psychiatrists toward etiological theories of schizophrenia: 1975-1985. Joumal of Clinical Psychology 43. 438-443.

Gray A.J. (2002). Stigma in psychiatry. Journal of the Royal Societr of Medicine 95. 72-76.

Heresco-Levy U., Ermilov M., Giltsinsky B.. Lichtenstein M. \& Blander D. (1999). Treatment-resistant schizophrenia and staff rejection. Schisophrenia Bulletin 25, 457-465.
Hocking B. (2003). Reducing mental illness stigma and discrimination - everybody's business. Medical Joumal of Australia 178. Suppl.. S47-48.

Jorm A.F., Korten A.E., Jacomb P.A.. Rodgers B. \& Pollitt P. (1997). Beliefs about the helpfulness of interventions for mental disorders: a comparison of general practitioners, psychiatrists and clinical psychologists. Australian and New Zealand Journal of Psychiary 31. 844-851.

Jorm A.F.. Korten A.E.. Jacomb P.A.. Christensen H. \& Henderson S. (1999). Attitudes towards people with a mental disorder: a survey of the Australian public and health professionals. Australian and New. Zealand Journal of Psychiatry 33. 77-83.

Kendrick T., Millar E. Burns T., Ross F. (1998). Practice nurse involvement in giving depot neuroleptic injections: development of a patient assessment and monitoring checklist. Primary Care Psychiary 4, 149-154.

Lambert T.. Brennan A., Castle D., Kelly D.L. \& Conley R.R. (2003). Perception of depot antipsychotics by mental health professionals. Jounal of Psychiaric Practice 9, 252-260

Landeen J., Kirkpatrick H., Woodside H., Byrne C., Bernardo A. \& Pawlick J. (1996). Factors influencing staff hopefulness in working with people with schizophrenia. Issues in Mental Health Nursing 17 , 457-467.

Lawrie S.M., Parsons C., Patrick J., Masson S., Sussmann J., Cumming D., Lewin J. \& Pickup S. (1996). A controlled trial of general practitioners' attitudes to patients with schizophrenia. Health Bulletin 54, 201-203.

Lawrie S.M., Martin K., McNeill G., Drife J., Chrystie P., Reid A., Wu P., Nammary S. \& Ball J. (1998). General practitioners' attitudes to psychiatric and medical illness. Psychological Medicine 28, 1463 1467.

Llerena A., Caceres M.C. \& Penas-Lledo E.M. (2002). Schizophrenia stigma among medical and nursing undergraduates. European Psychiatry 17, 298-299.

Lewis G., Croft-Jeffreys C. \& David A. (1990). Are British psychiatrists racist? British Journal of Psychiatry 157, 410-415.

Link B.G. (2001). Stigma: many mechanisms require multifaceted responses. Epidemiologia e Psichiatria Sociale 10. 8-11.

Lucas R. (2003). Psychoanalytic controversies the relationship between psychoanalysis and schizophrenia. International Journal of Psychoanalysis 84, 3-9.

Magliano L., De Rosa C. Guarneri M., Cozzolino P., Malangone C., Marasco C., Fiorillo A., Maj M. \& Gruppo di Lavoro (2002). Causes and psychosocial consequences of schizophrenia: the opinions of mental health services' staff. Epidemiologia e Psichiatria Sociale $11,35-44$.

McLeod.H.J.. Deane F.P. \& Hogbin B. (2002). Changing staff attitudes and empathy for working with people with psychosis. Behavioural and Cognitive Psychotherapy 30, 459-470.

Michels R. (2003). The relationship between psychoanalysis and schizophrenia by Richard Lucas - a commentary. International Joumal of Psychoanalysis 84, 9-12.

Mirabi M., Weinman M.L.. Magnetti S.M. \& Keppler K.N. (1985). Professional attitudes toward the chronic mentally ill. Hospital and Community Psychiatry 36, 404-405.

Mukherjee R.. Fialho A.. Wijetunge A., Checinski K. \& Surgenor T. (2002). The stigmatisation of psychiatric illness: the attitudes of medical students and doctors in a London teaching hospital. Psychiatric Bulletin 26. 178-181.

Murray M.G. \& Steffen J.J. (1999). Attitudes of case managers toward people with serious mental illness. Community Mental Health 
Joumal 35. 505-514.

Ono Y.. Satsumi Y.. Kim Y.. Iwadate T.. Moriyama K.. Nakane Y.. Nakata T.. Okagami K.. Sakai T.. Sato M.. Someya T.. Takagi S.. Ushijima S.. Yamauchi K. \& Yoshimura K. (1999). Schizophrenia: is it time to replace the term? Psychiatry and Clinical Neurosciences 53. 335-341

Packer S.. Prendergası P.. Wasylenski D.. Toner B. \& Ali A. (1994). Psychiatric residents attitudes towards patients with chronic mental illness. Hospital and Community Psychiarry 32. 767-775.

Patel M.X.. Nikolaou V.\& David A.S. (2003a). Psychiatrists" attitudes to maintenance medication for patients with schizophrenia. Psichological Medicine 33. 83-89.

Patel M.X.. Nikolaou V. \& David A.S. (2003b). Eliciting psychiatrists beliefs about side effects of typical and atypical antipsychotic drugs. International Joumal of Psichiatry in Clinical Practice 7. 117-120.

Patel M.X. \& David A.S. (in press). Why aren't depot antipsychotics prescribed more often. and what can be done about it? Advances in Psichiatric Treatment.

Sartorius N. (2002). Iatrogenic stigma of mental illness. British Medical Journal 324. 1470-1471.

Schulze B. \& Angermeyer M.C. (2003). Subjective experiences of stigma. A focus group study of schizophrenic patients. their patients and mental health professionals. Social Science and Medicine 56. 299312.

Sevigny R.. Yang W., Zhang P.. Marleau J.D., Yang Z.. Su L., Li G.,
Xu D.. Wang Y. \& Wang H. (1999). Attitudes toward the mentally ill in a sample of professionals working in a psychiatric hospital in Beijing (China). International Joumal of Social Psychiatry 45. 41 55 .

Summerfield D. (2001). Does psychiatry stigmatizc? Journal of the Roval Society of Medicine 94. 148-149.

Thompson A.H.. Stuart H.. Bland R.C.. Arboleda-Florez J.. Warner R. \& Dickson R.A. (2002). Attitudes about schizophrenia from the pilot site of the WPA worldwide campaign against the stigna of schizophrenia. Social Psychiatry \& Psychiatric Epidemiology 37. 475-482.

Walburn J.. Gray R.. Gournay K.. Quraishi S. \& David A.S. (2001). A systematic review of patient and nurse attitudes to depot antipsychotic medication. British Journal of Psychiamy 179. 300-307.

Walter G. (1998). The attitude of health professionals towards carers and individuals with mental illness. Australasian Psychiatry 6. 7072

Watson C.G.. Daly W. \& Zimmerman A. (1980). Staff attitudes and treatment effectiveness. Journal of Clinical Psychology 36, 601605 .

Woodside H.. Landeen J., Kirkparrick H.. Byrne C., Bernardo A. \& Pawlick J. (1994). Hope and schizophrenia: exploring attitudes of clinicians. Psychosocial Rehabilitation Joumal 18. 140-144.

www.openthedoors.com (2004). Retrieved August 17. 2004. from http:// www.openthedoors.com 